\title{
In situ sampling of interstitial water from lake sediments
}

\author{
Albertus G. Brinkman, Wim van Raaphorst \& Lambertus Lijklema \\ Twente University of Technology, Department of Chemical Technology, P.O. Box 217, 7500 AE Enschede, \\ The Netherlands
}

Keywords: lake sediments, pore water, sampling, technique

\begin{abstract}
A sampler with a relatively high resolution has been developed, which allows interstitial water to be obtained from lake sediments at well defined depths, without serious disturbance of sediment structure. Oxidation effects are excluded. Sampling time is in the order of a day. Installation requires little additional equipment. The instrument has been developed for use in shallow lakes.
\end{abstract}

\section{Introduction}

Transport of dissolved materials across the sediment-water interface is an important factor, affecting the chemical characteristics of lakes. In studying transport processes, pore water concentrations and concentration gradients in the sediment have to be known. Modelling of such processes, including for example chemical interactions and biochemical degradation, makes it possible to relate transport coefficients and concentration gradients, and to calculate fluxes across the interface. These fluxes, in turn, can be related to measured concentrations in the lake water.

In our investigation of a partly artificial and shallow lake, with an average depth of about $1 \mathrm{~m}$, mass budget studies showed a net phosphorus release from the sediment during summer, whereas in winter the sediment acts as a sink. The ultimate goal of our study is to assess all the important mechanisms, and integrated modelling will be used to estimate the effect of management measures.

In this contribution we describe a new sampling device which is being used to sample sediment pore water.

\section{Features}

The important features of a pore water sampler should include: minimal disturbance of the sediment-water interface and sediment structures; prevention of oxidation of anoxic pore waters; little or no change in temperature or pressure, especially when analysis of dissolved gases is required; sufficient sample volume (depending on the desired analyses); minimal water-flow (streaming) through the sediments; high resolution because gradients, especially those close to the interface, can be rather steep.

Most types of existing instrumentation meet only a few of these needs. A short discussion of some of the draw-backs and advantages, of existing equipment, precedes the description of the newly developed apparatus.

\section{Existing techniques}

A distinction can be made between instruments that sample sediment (a) from which pore water can be obtained in the laboratory, and in situ samplers (b, c). 


\section{a) Coring}

A tube is pushed into the sediment (by a bar or under its own weight), closed by some mechanism, recovered on board a ship, and transported to the laboratory; the sediment is then cut into slices and squeezed (Rheeburgh 1967; Fast \& Wetzel 1974; Robbins \& Gustinis 1976). Although this method has certain advantages, notably that the sediment is also sampled so the pore water concentration can be directly related to sediment composition, there are major draw-backs. For example, oxidation may occur (Loder et al. 1978); during squeezing, a change in the carbon dioxide content may take place, which will cause a change in pore water composition; also, organisms are squeezed. During transport, temperature changes are difficult to prevent. Sometimes, instead of squeezing, pore water is collected with a syringe, pushed through a sealed opening in the tube wall. Unfortunately, good fluid recoveries are not easy; particulates may be included in the sample (where they can distort concentration values), and particulates may clog both syringe samplers and preventive filter screens.

\section{b) Dialysis (in situ)}

A half-open container (Mayer 1976) or sheet (Hesslein 1976), containing one or more dialysis bags, is pushed into the sediment, and left there for some days. The attractive features of this method are, among others, that no pore water flow is induced in the sediment by sampling, and analysis of dissolved gases is possible. But, for our purpose, the very long equilibration time required for samples of $5-10 \mathrm{ml}$ is rather unsatisfactory, and so is the disturbance of sediment structure. The size of the dialysis samplers is also relatively large, in comparison to the sediment layer structures.

\section{c) Direct-suction sampling (in situ)}

Goodman (1979) described an apparatus that directly sampled pore water from sandy sediments: the water inlet, a probe with a $45 \mathrm{~m}$ mesh size of $3 \mathrm{~mm}$ diameter, is pushed into the sediment. A $1 \mathrm{~mm}$ internal diameter PVC capillary tube connects this probe with a syringe, in which the water is collected. The instrument is simple and easy to handle, and also allows sampling at a fairly well defined depth. However, fine particulate material is also collected, and reduction of the mesh size may cause clogging. Oxidation effects are hard to prevent.

\section{Design}

The instrument, described here, is an in situ sampler. It is relatively easy to operate, and combines most of the positive features of the samplers mentioned previously. Figures 1 and 2 show the frame and probe, respectively; up to ten probes may be attached to the frame. The material is stainless steel, which allows the sampler to be pushed into relatively hard, sandy sediments. The screw connections, especially, require the use of strong materials.

The probe consists of two $10-\mathrm{mm}$-diameter tubes. The total sample volume of the lower part is $7-10 \mathrm{ml}$; the length of this lower part is $15-20 \mathrm{~cm}$. The length of the second tube can be adjusted, according to the desired sampling depth. One or more paper or glass fiber filters, with a $5 \mathrm{~mm}$ circu-

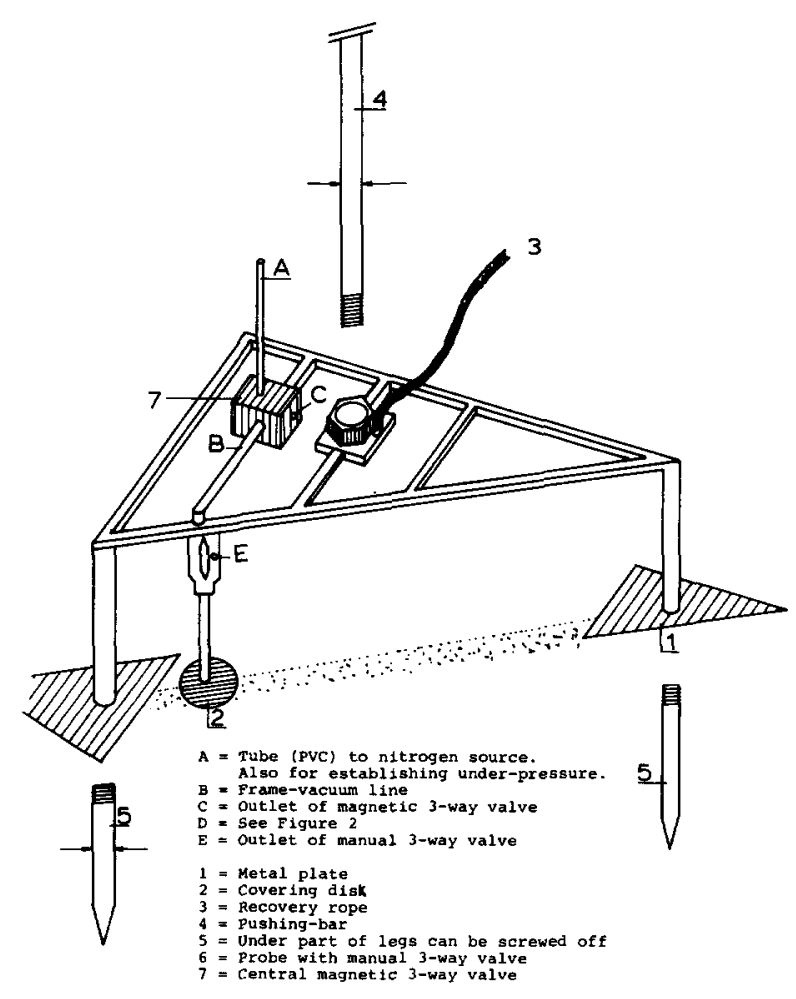

Fig. 1. Outline of the frame. 


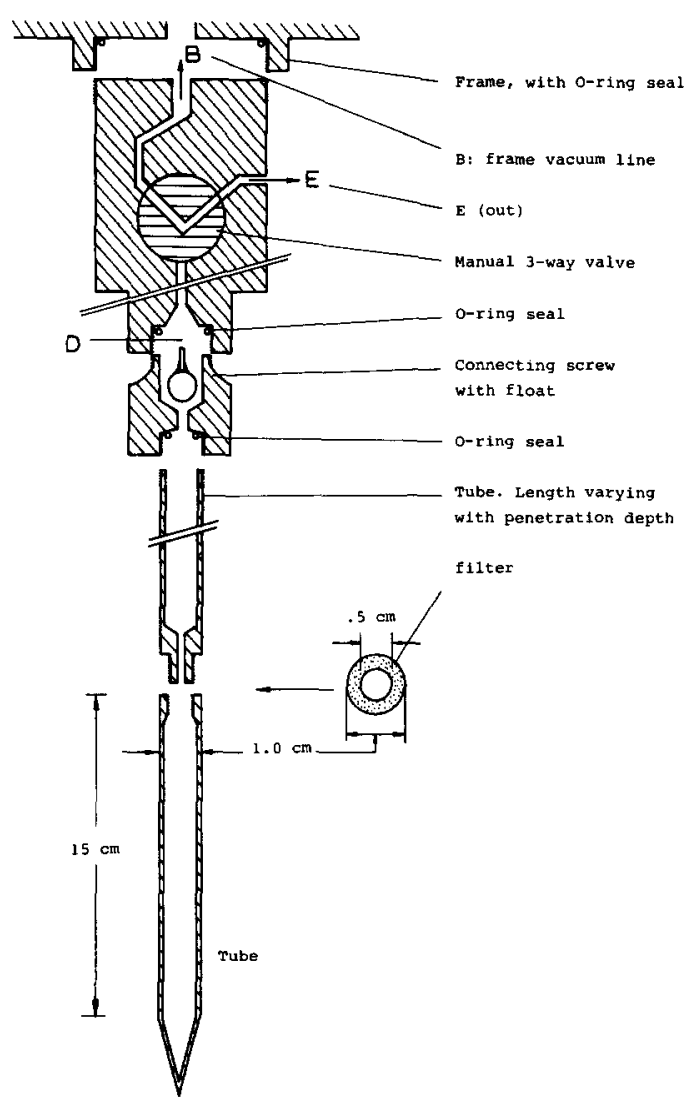

Fig. 2. Outline of the probe.

lar hole, can be placed between both tubes. The sample intake is less than $1 \mathrm{~mm}$ high. The sample filters horizontally through the filter paper, and in our probe the filter thickness is $2.5 \mathrm{~mm}$. Three vertical grooves in the screwthread allow the pore water to enter tube 1.

The screw that connects these tubes with a manual valve, contains a float. When the sampler fills up, this float prevents further inflow of water, while other probes that are connected to the vacuum lines of the frame, are not affected. The manual valve is used for flushing with nitrogen (see below).

The frame with probes has to be pushed into the sediment with a bar. Metal plates on the three legs prevent it from sinking into the mud. The plates and the lower part of the legs can be replaced; soft sediments require large plates and long legs. After installation the bar is unscrewed; a rope is used for recovery after sampling (see Fig. 1).

\section{Nitrogen flushing}

The probe (Fig. 2) is flushed with nitrogen, in the laboratory. The manual valve is closed and the sampling ring is sealed temporarily, and the probes are transported. The tubes on the frame and the upper part of the manual valve, which has been in contact with air, are flushed in the field. To perform this, first the main tube A (the magnetic three-way valve: $C=$ out) is flushed, then the magnetic valve is switched to position (A-B) and the remaining parts of the instrument are flushed. After switching the manual valve to position (B-D), all the probes are connected to the pressure line, and the instrument is ready for operation. Initially, a slight overpressure is maintained, so that no water can enter the filter opening.

\section{Installation}

After installation on the lake bottom, the sediment must re-adjust for a while. Then the pressure is reduced to a desired vale (in most cases the normal hydrostatic pressure will be sufficient, but for very low pressures some vacuum equipment is needed) - sampling now starts - and the magnetic three-way valve is switched off (position A-C).

Just before and after recovery, procedures are reversed.

\section{Additional equipment}

Little additional equipment is required. To switch the magnetic valve, a 5-12 V(DC) power source is needed (during both installation and recovery). If a large negative pressure is required, vacuum equipment will be necessary.

\section{Testing}

Some characteristics of this sampling procedure have been tested.

\section{a) Sampling rate}

The sampling rate is a function of the character of the sediment and the number and type of filters, and 
their compression between the upper and lower tubes. Since sediments usually show a vertical gradient, in grain size and porosity, the sampling rate is rather hard to control, within a narrow range. This means, that one probe may sample two or three times faster than another, and therefore, the float is used in order to prevent overflow.

\section{b) Adsorption}

Since stainless steel is an adsorbing material for several ion-types, coating of the inside of the sample probes (pins) is necessary. Figure 3 shows the good result of a polyethylene coating, made from an $8 \%$ solution in boiling n-octane.

\section{c) Streamlines}

It is important to know whether the sampled water originates from the depth of the sampling port, or whether it is a composite of water from a range of depths. Figure 4 shows some possible streamlines (lines of equal flow). Figure 4 a shows a relatively high velocity in the vertical direction. The reason for this is that there is little resistance to the vertical movement of water through the sediment. This property especially affects the results when sampling occurs just below the sediment-water interface, where steep vertical gradients exist. To meet this drawback we used a rubber 'covering disk' of approximately $6 \mathrm{~cm}$ diameter, which prevents vertical water flow when the sample opening is just

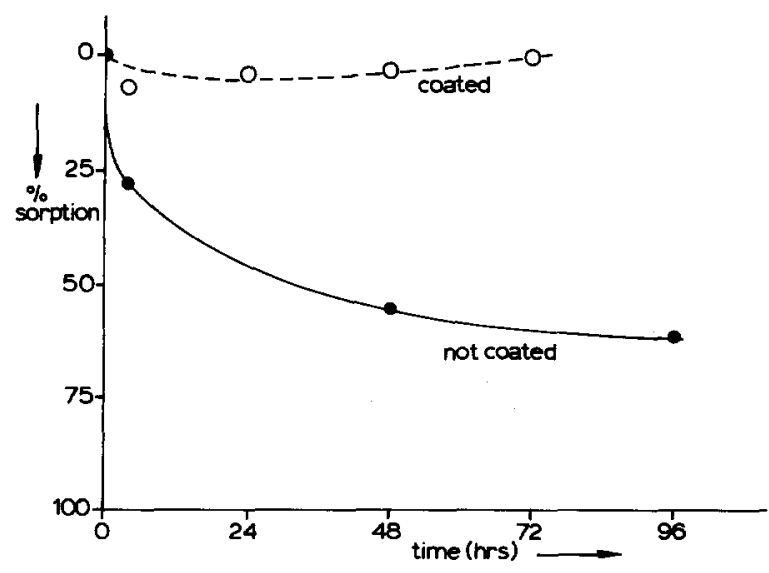

Fig. 3. Phosphate sorption in sampling probe (pin) as a function of time. $C_{0}=1 \mu \mathrm{g} \mathrm{g}^{-1} \mathrm{P}$.
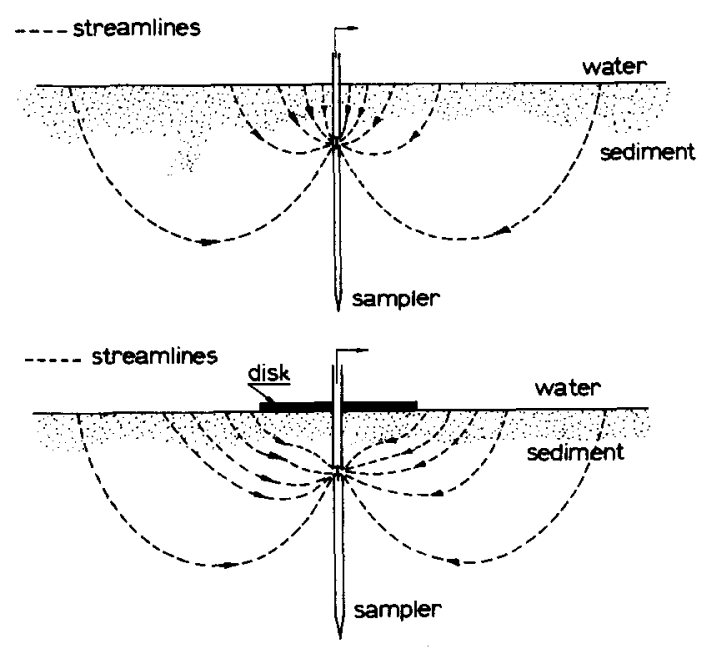

Fig. 4. Some possible streamlines in the sediment, (a) without a covering disk, and (b) when using a covering disk.

below the interface. Figure $4 \mathrm{~b}$ illustrates possible streamlines, in this case.

Table 1 shows the influence of such a covering disk on conductivity measurements. The sediment which was mixed with potassium chloride (in order to establish a high conductivity) and the overlying water (with a low conductivity) were both sampled. In nine out of the ten experiments the probe (pin), without a covering disk, sampled water of lower conductivity than the probe (pin) with a covering disk. The only reason for this can be that the unco-

Table 1. Conductivity measurements as an example of the need to use a covering disk (about $5-7 \mathrm{~cm}$ diameter), in order to prevent bulk inflow of water. The mean depth of the two upper probes (pins) is about $4 \mathrm{~mm}$, that of the lowest probe (pin) is about $6 \mathrm{~cm}$. Data in $\%$ of the highest value.

\begin{tabular}{|c|c|c|c|c|}
\hline $\begin{array}{l}\text { Measurement } \\
\text { No. }\end{array}$ & $\begin{array}{l}\text { Bulk } \\
\text { water }\end{array}$ & $\begin{array}{l}\text { Sediment } \\
(0.4 \mathrm{~cm}, \\
\text { uncovered })\end{array}$ & $\begin{array}{l}\text { Sediment } \\
(0.4 \mathrm{~cm}, \\
\text { covered } \\
\text { with disk })\end{array}$ & $\begin{array}{l}\text { Sediment } \\
(6 \mathrm{~cm})\end{array}$ \\
\hline 1 & 41 & $?$ & 93 & 100 \\
\hline 2 & 34 & 42 & 54 & 100 \\
\hline 3 & 6 & 51 & $?$ & 100 \\
\hline 4 & 12 & 28 & 35 & 100 \\
\hline 5 & 39 & 80 & 61 & 100 \\
\hline 6 & 38 & 51 & 60 & 100 \\
\hline 7 & 66 & 68 & 100 & 92 \\
\hline 8 & 5 & 68 & 92 & 100 \\
\hline 9 & 10 & 31 & 89 & 100 \\
\hline 10 & 14 & 23 & 47 & 100 \\
\hline
\end{tabular}


vered probe sampled much of the overlying water, although it was below the sediment surface. We recommend the use of a cover. The resolution of sampling has to be estimated, because it is difficult to construct theoretical streamlines. We estimate that, when a sample volume of about $10 \mathrm{ml}$ is desired, the sampled water originates from a region less than $0.6 \mathrm{~cm}$ from the opening depth. Even when a covering disk is used, some of the water appears to originate from a depth which is a little higher than the opening depth. The measured concentrations are, therefore, not quite those existing at that intake depth, but rather they are a mixture of concentrations at the intake depth and at a level a few millimetres above and below it. It should be mentioned also that water, coming from other depths, has to flow slowly through the sediment towards the sample opening. Hence, some of the original differences in pore water quality will be lost because of chemical equilibration.

d) As an example, we sampled a sand column with a known conductivity gradient. In a $60 \mathrm{~cm}$ tall column, a conductivity gradient was established and the pore water was sampled and analysed. Afterwards the conductivity was also measured directly. Figure 5 shows a fairly good agreement between both.

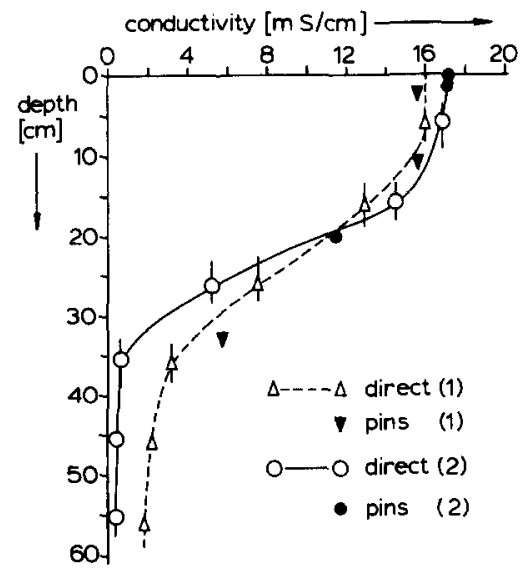

Fig. S. Conductivity profile of a sand column, measured directly and after sampling with probes (pins), respectively.

\section{Concluding remarks}

We feel that this new instrument offers several advantages over many of the currently available pieces of equipment, especially in its ability to handle problems caused by oxidation, temperature change, sample volume size and sediment disturbance. Of course there are restrictions to the use of the apparatus. In extremely soft sediments, special care has to be taken to prevent it from sinking into the mud. Its use is also largely limited to shallow lakes (e.g. less than about $10 \mathrm{~m}$ depths). In our opinion, however, the high resolution of this sampler, together with an ability to maintain (largely) ambient conditions, make it a particularly useful apparatus for studying pore water characteristics and sediment/ water interfaces.

\section{Acknowledgements}

We wish to thank G. J. G. Krabbe for suggestions about the construction, R. H. Arends for making the figures, J. H. E. A. Grob for typing the manuscript and C. Slappendel for the grammatical corrections.

\section{References}

Fast, A. W. \& Wetzel, R. G., 1974. A close-interval fractionator for sediment cores. Ecology 55: 202-204.

Goodman, K. S., 1979. An apparatus for sampling interstitial water throughout tidal cycles. Hydrobiol. Bull. 13: 30-33.

Hesslein, R. H., 1976. An in situ sampler for close interval pore water studies. Limnol. Oceanogr. 21: 912-914.

Loder, T. C., Lyons, W. B., Murray, S. \& McGuinness, H. D., 1978. Silicate in anoxic pore waters and oxidation effects during sampling. Nature 273: 373-374.

Mayer, L. M., 1976. Chemical water sampling in lakes and sediments with dialysis bags. Limnol. Oceanogr. 21:909-912.

Reeburgh, W. S., 1967. An improved interstitial water sampler. Limnol. Oceanogr. 12: 163-165.

Robbins, J. A. \& Gustini, J., 1976. A squeezer for efficient extraction of pore water from small volume of anoxic sediment. Limnol. Oceanogr. 21: 905-909.

Sayles, F. L., Mangelsdorf, P. C., Wilson, T. R. S. \& Hume, D. N., 1976. A sampler for the in situ collection of marine sedimentary pore waters. Deep-sea Res. 23: 259-264. 